\title{
Increased recovery of brain acetylcholinesterase activity in dichlorvos-intoxicated European eels Anguilla anguilla by bath treatment with $N$-acetylcysteine
}

\author{
Samuel Peña-Llopis ${ }^{1, *}, M^{a}$. Dolores Ferrando ${ }^{2}$, Juan B. Peña ${ }^{1}$ \\ ${ }^{1}$ Institute of Aquaculture Torre de la Sal (CSIC), 12595 Ribera de Cabanes (Castellón), Spain \\ ${ }^{2}$ Department of Animal Biology (Animal Physiology), Faculty of Biology, University of Valencia, Dr. Moliner-50, \\ 46100 Burjassot (Valencia), Spain
}

\begin{abstract}
Organophosphate (OP) pesticides are widely used as antiparasitic chemicals in finfish aquaculture. However, current antidotes cannot be applied to treat intoxicated fish. We showed in previous studies the importance of glutathione (GSH) metabolism in pesticide resistance of the European eel Anguilla anguilla L. The present work studied the effects of the antioxidant and glutathione pro-drug $N$-acetyl-L-cysteine (NAC) on the recovery of European eels exposed for $96 \mathrm{~h}$ to a sublethal concentration $\left(0.17 \mathrm{mg} \mathrm{l}^{-1} ; 20 \%\right.$ of its $96 \mathrm{~h} \mathrm{LC}_{50}$ ) of the OP pesticide dichlorvos (2,2-dichlorovinyl dimethyl phosphate; DDVP). This insecticide and acaricide decreased muscular GSH content and increased oxidised glutathione (GSSG), lowering the GSH:GSSG ratio, which is indicative of a condition of oxidative stress. Acetylcholinesterase (AChE) and glutathione reductase (GR) activities in the brain, which were biomarkers of neurotoxicity and oxidative stress, respectively, were also highly inhibited. Recovery in a $0.5 \mathrm{mM}\left(81.6 \mathrm{mg} \mathrm{l}^{-1}\right)$ NAC concentration ameliorated muscular GSH depletion, GSH:GSSG ratio, and the inhibition of brain AChE and GR activities. Hence, this is the first evidence of improved recovery of organophosphate-poisoned fish by bath treatments.
\end{abstract}

KEY WORDS: Detoxification • Organophosphorus pesticide • Organophosphate poisoning • Cholinesterase inhibitor $\cdot$ Oxidative stress $\cdot N$-acetyl-L-cysteine $\cdot$ AChE $\cdot$ Glutathione metabolism

\section{INTRODUCTION}

The rapid growth and development of intensive aquaculture has been concomitant to the use of chemicals to deal with animal health. Parasitic infestations cause fish stress and susceptibility to secondary infections, producing significant losses to the industry. Among the existing veterinary drugs and chemicals, the organophosphate (OP) insecticide and acaricide dichlorvos have been extensively used to treat sea lice infestations (by the copepod parasites Lepeophtheirus salmonis and Caligus elongatus) in the Atlantic salmon Salmo salar culture because it is relatively non-persistent and undergoes fast and complete hydrolysis in most environments, being rapidly metabolised (WHO 1989).
The primary effects of dichlorvos and other OPs on organisms are through the inhibition of the enzyme acetylcholinesterase (AChE), which is responsible for terminating the transmission of the nerve impulse. Hence, AChE inhibition is an established biomarker of $\mathrm{OP}$ and carbamate exposure that is more reliable than the analytical determination of pesticide content for the diagnosis of poisoning, because it accounts for a physiological effect directly linked to the compound toxic mode of action and persists much longer than pesticides in environmental samples (Fulton \& Key 2001). However, OP toxicity in general implies more than AChE inhibition, since Bagchi et al. (1995) found that different classes of pesticides may induce in vitro and in vivo generation of reactive oxygen species (ROS). They are mainly hydrogen peroxide $\left(\mathrm{H}_{2} \mathrm{O}_{2}\right)$, 
superoxide $\left(\mathrm{O}_{2}{ }^{-}\right)$, and hydroxyl radical (HO·), which are able to react with biological macromolecules (especially the hydroxyl radical) and cause enzyme inactivation, lipid peroxidation and DNA damage. The balance between ROS production and antioxidant defences determines the degree of oxidative damage. In fact, dichlorvos has induced oxidative-stress effects in carp Cyprinus carpio and catfish Ictalurus nebulosus (Hai et al. 1997).

In previous studies we demonstrated that thiocarbamate herbicides induced oxidative stress in the European eel Anguilla anguilla L., and we highlighted the importance of glutathione metabolism in the tolerance to these pesticides (Peña-Llopis et al. 2000, 2001). Glutathione is a ubiquitous thiol-containing tripeptide that is involved in numerous processes essential for normal biological functioning, such as the detoxification of electrophilic xenobiotics and free-radical scavenging (Meister \& Anderson 1983). Gluthatione is predominantly present in cells in its active and reduced form (GSH), but as a consequence of oxidising conditions, 2 molecules of GSH are linked by a disulfide bond to comprise a molecule of oxidised glutathione (GSSG). The GSH:GSSG ratio, or glutathione redox status, is then considered an index of the cellular redox status and a biomarker of oxidative damage, because glutathione maintains the thiol-disulphide status of proteins, acting as a redox buffer.

As we found previously, those eels that enhanced GR activity, increased GSH, and maintained the GSH:GSSG ratio in liver showed a higher survival upon herbicide exposure (Peña-Llopis et al. 2001). A drug that could increase the GSH content and act as a reductant would improve the tolerance of OP-poisoned fish. $N$-acetyl-L-cysteine (NAC) is a known antioxidant and free-radical scavenger that can easily be deacetylated to L-cysteine, the limiting amino acid for glutathione synthesis. This antioxidant extended the survival of Anguilla anguilla exposed to a lethal concentration of dichlorvos because it enhanced glutathione metabolism (Peña-Llopis et al. in press).

The main objective of this work was to evaluate the effect of the antioxidant NAC on the recovery of European eels intoxicated with a sublethal concentration of dichlorvos.

\section{MATERIALS AND METHODS}

Experimental animals. Young yellow eels of the species Anguilla anguilla (10 to $20 \mathrm{~g}$ weight), which were sexually undifferentiated at this stage of development, were used to avoid the effects of sex variation and minimise hormonal interactions in toxicity assays. These European eels were obtained from a fish farm (Valen- ciana de Acuicultura S.A., Puzol, Spain) free from any disease. Eels were acclimatised to laboratory conditions, according to OECD guidelines (1992), for $2 \mathrm{wk}$ before starting experiments in aerated and filtered dechlorinated freshwater (total hardness: $198 \pm 5 \mathrm{mg}$ $1^{-1}$ as $\mathrm{CaCO}_{3 i}$ pH: $7.4 \pm 0.1$; dissolved oxygen: $7.2 \pm 0.1$ $\mathrm{mg} \mathrm{l}^{-1}$ ) at $24.0 \pm 0.5^{\circ} \mathrm{C}$, and with a $12 \mathrm{~h}$ photoperiod. Fish did not respond to feeding attempts during the acclimatisation period (Van Waarde et al. 1983, Ferrando 1990).

Chemicals. Dichlorvos (2,2-dichlorovinyl dimethyl phosphate; DDVP) was obtained from Laboratorios Hipra S.A. (Girona, Spain) as an emulsifiable concentrate which contained $40 \%$ of the parent pesticide (Hexipra Solucion ${ }^{\circledR}$ ). 2-vinylpyridine was acquired from Aldrich. NADPH was purchased from Applichem. NAcetyl-L-cysteine and all other reagents were obtained from Sigma Chemical, unless mentioned otherwise.

Experimental procedure. Initial experiments were performed in order to choose the best concentrations of the pesticide and the antioxidant for the study of exposure and recovery. Previous concentration-effect experiments indicated that the median lethal concentration at $96 \mathrm{~h}\left(96 \mathrm{~h} \mathrm{LC}_{50}\right)$ for dichlorvos in the European eel was $0.852 \mathrm{mg} \mathrm{l}^{-1}$ (95\% CI, 0.735 to 0.957 ) (PeñaLlopis et al. in press). A sublethal concentration of dichlorvos of $0.17 \mathrm{mg} \mathrm{l}^{-1}$ of the active ingredient, which corresponded to $20 \%$ of the $96 \mathrm{~h} \mathrm{LC}_{50}$, was selected for all the experiments with the aim of allowing a better comparison between groups in the recovery period. As the pesticide formulation contained $8 \%$ of emulgators and $47 \%$ of non-toxic solvents, composed principally by 2-propanol (Laboratorios Hipra S.A. pers. comm.), controls were exposed to similar solvent conditions, that is, $0.2 \mathrm{mg} \mathrm{l}^{-1}$ of 2-propanol. This concentration is 40000 times lower than the $96 \mathrm{~h} \mathrm{LC}_{50}$ s for freshwater fish, which ranged from 4200 to $11130 \mathrm{mg} \mathrm{l}^{-1}$ (WHO 1990), thus the inclusion of another control group without the solvent was unnecessary.

Two experimental procedures were conducted to choose the NAC concentration for the recovery experiment. Firstly, fish were exposed for $48 \mathrm{~h}$ to several concentrations of NAC $(0,0.1,1$, and $10 \mathrm{mM}$, which corresponded to $0,16.32,163.2$, and $1632 \mathrm{mg} \mathrm{l}^{-1}$, respectively) in order to compare the GSH levels in the liver and muscle. Secondly, fish were exposed to a sublethal concentration of dichlorvos $\left(0.17 \mathrm{mg} \mathrm{l}^{-1}, 20 \%\right.$ $96 \mathrm{~h} \mathrm{LC}_{50}$ ) for $48 \mathrm{~h}$ and then transferred to $0,0.1,0.5$, and $1 \mathrm{mM}\left(0,16.32,81.6\right.$, and $163.2 \mathrm{mg} \mathrm{l}^{-1}$, respectively) NAC solutions for $48 \mathrm{~h}$. As discussed below in the 'Results' section, the most suitable concentration of NAC was $0.5 \mathrm{mM}\left(81.6 \mathrm{mg} \mathrm{l}^{-1}\right)$.

Five groups of animals were used: (1) Controls: these animals received no treatment but were maintained in the same solvent environment (2-propanol, $0.2 \mathrm{mg} \mathrm{l}^{-1}$ ) 
for $96 h_{i}$ (2) NAC: fish were exposed to $0.5 \mathrm{mM}$ NAC and $0.2 \mathrm{mg} \mathrm{l}^{-1}$ of 2-propanol for $96 \mathrm{~h}_{i}$ (3) Dichlorvos: fish were exposed to a sublethal concentration of dichlorvos (0.17 $\mathrm{mg} \mathrm{l}^{-1}, 20 \% 96 \mathrm{~h} \mathrm{LC}_{50}$ ) for $96 \mathrm{~h}_{i}$ (4) D + Water: fish were exposed to $0.17 \mathrm{mg} \mathrm{l}^{-1}$ dichlorvos for $96 \mathrm{~h}$ and then transferred to clean water for $96 \mathrm{~h}_{\text {; }}$ (5) D + NAC: fish were exposed to $0.17 \mathrm{mg} \mathrm{l}^{-1}$ dichlorvos for $96 \mathrm{~h}$ and then transferred to a $0.5 \mathrm{mM}\left(81.6 \mathrm{mg} \mathrm{l}^{-1}\right.$ ) NAC solution for $96 \mathrm{~h}$.

All groups were maintained per duplicate in 401 glass aquaria at $24.0 \pm 0.5^{\circ} \mathrm{C}$ in a static-renewal system, in accordance with OECD guidelines (1992), where water and either the pesticide or NAC were completely replaced every $24 \mathrm{~h}$. No mortality was observed during the experiment, but fish exposed to the pesticide showed convulsions, tremors and erratic swimming. In all, 5 to 6 individuals were removed from each group at $3,6,12,24,48$, and $96 \mathrm{~h}$ after treatment, which corresponded to the 99,102,108,120,144, and $192 \mathrm{~h}$ for the D + Water and D + NAC groups, and were anaesthetised in ice instead of with chemical anaesthesia because the latter could interfere with glutathione metabolism (Brigelius et al. 1982). They were then weighed, the length measured, and euthanised by decapitation. The brain and muscle were excised, weighed and stored frozen at $-80^{\circ} \mathrm{C}$ until the biochemical determinations were performed.

Glutathione determination. Liver and muscle were homogenised with 5 volumes of ice-cold $5 \% 5$-sulfosalicylic acid $\mathrm{g}^{-1}$ wet wt tissue, and further processed by sonication (Vibra-Cell, Sonics \& Materials). Homogenates were then centrifuged at $20000 \quad g$ for $10 \mathrm{~min}$ at $4{ }^{\circ} \mathrm{C}$. Total glutathione content (tGSx) and GSSG were determined in supernatant fractions with a sensitive and specific assay using a recycling reaction of GSH with 5,5'-dithiobis(2-nitrobenzoic acid) (DTNB) in the presence of excess glutathione reductase according to Baker et al. (1990) in a microplate reader (Model 3550, Bio-Rad Laboratories) as previously described (Peña-Llopis et al. 2001). Glutathione concentrations were expressed as nmol of GSH equivalents (GSx) per mg of protein $(\mathrm{GSx}=[\mathrm{GSH}]+2$ [GSSG]). GSH was calculated by subtracting GSSG levels from the tGSx levels determined. The GSH:GSSG ratio was expressed as number of molecules, but not moles: GSH:GSSG = (tGSx - GSSG)/ (GSSG/2).

Enzyme assays. Brain tissues were homogenised with 10 volumes of Henriksson stabilising medium (Henriksson et al. 1986), which contained $50 \%$ glycerol, $20 \mathrm{mM}$ phosphate buffer $\mathrm{pH} 7.4,0.5$ mM EDTA, and $0.02 \%$ defatted bovine serum albumin. -Mercaptoethanol was not included because it interferes with the GR assay. Homogenates were centrifuged at $20000 \mathrm{~g}$ for $20 \mathrm{~min}$. at $4^{\circ} \mathrm{C}$, and the resulting super- natants were diluted 5-fold with buffer and assayed rapidly for enzyme activities. AChE (EC 3.1.1.7) activity was determined with acetylthiocholine as substrate, in accordance to an adaptation of the Ellman method (Ellman et al. 1961) to microtiter plates by Doctor et al. (1987), but with $0.1 \mathrm{M}$ phosphate buffer, pH 7.27 and 1 mM EDTA as recommended by Riddles et al. (1979). Eel cholinesterase activity detected was considered as true AChE, as was previously characterised (Ferenczy et al. 1997). GR (EC 1.6.4.2) activity was assayed by the method of Cribb et al. (1989) with the following final concentrations: $[\mathrm{DTNB}]=0.075 \mathrm{mM}_{i}[\mathrm{NADPH}]=$ $0.1 \mathrm{mM}$; [GSSG] $=1 \mathrm{mM}$ according to Smith et al. (1988). A calibration curve of known activities of purified enzymes was used on every 96-well plate to avoid miscalculations that stem from an ill-defined path length. AChE (Type V) from electric eel Electrophorus electricus and GR (Type III) from baker's yeast were used as standards, whose activities were determined in quartz cuvettes using a Hitachi U-2001 UV/Vis spectrophotometer (Hitachi Instruments). A molar absorption coefficient at $412 \mathrm{~nm}$ ( ${ }_{412}$ ) of 14.150 was used for the dianion of DTNB (TNB ${ }^{2-}$ ) as Riddles et al. (1979) determined. Specific enzyme activities were expressed as nmoles of substrate hydrolysed per min per mg protein ( $\mathrm{mU} \mathrm{mg} \mathrm{m}^{-1}$ prot).

Protein determination. Protein content was determined by the Bio-Rad Protein Assay kit (Bio-Rad Laboratories) based on the Bradford dye-binding procedure, using bovine serum albumin as standard.

Statistical analyses. NAC solutions in preliminary experiments were compared to controls by the Dunnett's test using the SPSS 10.0 statistical software package, which was used for all the other statistical analyses. The 2-factor ANOVA with the Type III sumof-squares method by means of multivariate general linear models (GLM) were used to investigate the effect of time and exposure to dichlorvos and/or NAC and their interaction on biochemical parameters. A priori contrasts between selected levels of factors were made to compare means at specific exposure times. The GSH:GSSG ratios were log-transformed when they showed heterogeneity of variances according to the Levene test.

\section{RESULTS}

\section{Preliminary experiments}

Early experiments were performed to choose the most suitable NAC concentration for recovery from OP intoxication. Fish that were exposed to a $0.1 \mathrm{mM}$ NAC solution for $48 \mathrm{~h}$ did not alter their glutathione levels in the liver or muscle, whereas those that were 
treated with a $1 \mathrm{mM}$ concentration increased significantly the muscular GSH content ( $\mathrm{p}<0.05$; data not shown). However, all eels that were exposed to a 10 mM NAC solution died within the $48 \mathrm{~h}$, but glutathione levels at post-mortem time did not change significantly.

When fish were exposed to a sublethal concentration of dichlorvos $\left(0.17 \mathrm{mg} \mathrm{l}^{-1}, 20 \% 96 \mathrm{~h} \mathrm{LC}_{50}\right.$ ) for $48 \mathrm{~h}$ and subsequently transferred to a $0.1 \mathrm{mM}$ NAC solution for $48 \mathrm{~h}$, they did not present significant differences in glutathione levels in the liver or muscle compared to fish recovered in clean water (data not shown). Conversely, fish recovered in 0.5 and $1 \mathrm{mM}$ NAC solutions increased muscular GSH content ( $p<0.05)$. Furthermore, the $0.5 \mathrm{mM}$ NAC concentration increased the hepatic glutathione redox status (GSH:GSSG) $(\mathrm{p}<0.05)$. Therefore, a $0.5 \mathrm{mM}\left(81.6 \mathrm{mg} \mathrm{l}^{-1}\right)$ NAC concentration offered a better ratio of benefits:risks compared to $1 \mathrm{mM}$ and was selected for the subsequent experiments.

\section{Effect of NAC exposure}

The effect of the treatment of European eels with a $0.5 \mathrm{mM}$ NAC solution was an increase in muscular GSH content ( $p=0.006$; Table 1) and GSH:GSSG ratio ( $p=0.05$ ) without any significant change to GSSG levels $(p=0.65)$ nor brain AChE activity $(p=0.55)$. NAC treatment also positively influenced the GR activity $(\mathrm{p}=0.012)$.

When NAC-treated eels were compared to controls according to the sampling time, the GSH content in the muscle was increased by $29 \%$ from 48 to $96 \mathrm{~h}$ (Table 2), and the GSH:GSSG ratio was raised by $24 \%$ at $96 \mathrm{~h}$. However, NAC treatment produced no effect on GSSG levels or AChE activity, but increased significantly the GR activity by $29 \%$ from 48 to 96 h (data not shown).

\section{Effect of dichlorvos exposure}

Exposure of European eels to a sublethal concentration of the OP pesticide resulted in a significant decrease of muscular GSH content ( $p<0.0001$, Table 1) but an increase of GSSG ( $p=0.00011$ ) that oxidised dramatically the glutathione redox status $(\mathrm{p}<$ 0.0001), which is indicative of the cellular redox status. In addition, the GSH:GSSG ratio decreased over time $(\mathrm{p}<0.0001)$, and a significant interacting effect was found between time and dichlorvos exposure for glutathione redox status ( $p<0.0001$ ). AChE activity in brain was severely inhibited by the effect of the insecticide $(p<0.0001)$ and was time dependent $(p=0.024)$, with a significant time interaction $(p<0.0001)$. GR activity was also time-dependently $(p=0.005)$ inhibited as a consequence of the exposure to dichlorvos $(\mathrm{p}<0.0001)$.

When dichlorvos-exposed fish were compared to controls (Table 2, Figs. 1 \& 2), GSH and GSSG levels in muscle were significantly different from 24 to $96 \mathrm{~h}$ of exposure, whereas the GSH:GSSG ratio and brain GR activity decreased from $6 \mathrm{~h}$. However, AChE activity in the brain was inhibited from the beginning.

Table 1. Anguilla anguilla. F-statistics and corresponding p-values (in parentheses) of the 2-factor ANOVAs to test the effect of time and exposure to $0.17 \mathrm{mg} \mathrm{l}^{-1}$ dichlorvos and/or $0.5 \mathrm{mM} \mathrm{N}$-acetyl-L-cysteine (NAC) on several biochemical parameters of the European eel. GSH: reduced glutathione; GSSG: oxidised glutathione; AChE: acetylcholinesterase; GR: glutathione reductase

\begin{tabular}{|c|c|c|c|c|c|c|}
\hline \multirow[t]{2}{*}{ Contrast } & \multirow[t]{2}{*}{ Effect } & \multicolumn{3}{|c|}{ Muscle } & \multicolumn{2}{|c|}{ - Brain } \\
\hline & & GSH & GSSG & GSH:GSSG & $\mathrm{AChE}$ & GR \\
\hline NAC vs & Time & $2.2(0.07)$ & $0.55(0.74)$ & $1.66(0.16)$ & $2.2(0.07)$ & $1.50(0.21)$ \\
\hline \multirow[t]{2}{*}{ Control } & NAC & $8.1(0.006)$ & $0.21(0.65)$ & $4.0(0.05)$ & $0.37(0.55)$ & $6.7(0.012)$ \\
\hline & Time & $1.12(0.36)$ & $0.21(0.96)$ & $0.36(0.87)$ & $0.93(0.47)$ & $1.41(0.24)$ \\
\hline Dichlorvos vs & Time & $0.81(0.55)$ & $1.85(0.12)$ & $6.4(<0.0001)$ & $2.8(0.024)$ & $3.8(0.005)$ \\
\hline \multirow[t]{2}{*}{ Control } & Dichlorvos & $41(<0.0001)$ & $17.4(0.00011)$ & $136(<0.0001)$ & $194(<0.0001)$ & $35(<0.0001)$ \\
\hline & Time Dichlorvos & $1.52(0.20)$ & $1.79(0.13)$ & $8.0(<0.0001)$ & $8.1(<0.0001)$ & $0.32(0.90)$ \\
\hline D + Water vs & Time & $0.56(0.73)$ & $1.14(0.35)$ & $1.10(0.37)$ & $5.3(0.0006)$ & $1.12(0.36)$ \\
\hline \multirow[t]{2}{*}{ Control } & D + Water & $55(<0.0001)$ & $12(0.0012)$ & $81(<0.0001)$ & $445(<0.0001)$ & $42(<0.0001)$ \\
\hline & Time D + Water & $1.22(0.32)$ & $1.27(0.29)$ & $0.19(0.96)$ & $2.4(0.05)$ & $1.39(0.25)$ \\
\hline $\mathrm{D}+\mathrm{NAC}$ vs & Time & $2.6(0.038)$ & $0.62(0.68)$ & $1.79(0.13)$ & $8.6(<0.0001)$ & $0.80(0.56)$ \\
\hline \multirow[t]{2}{*}{ Control } & $\mathrm{D}+\mathrm{NAC}$ & $14.1(0.0005)$ & $14.7(0.0004)$ & $49(<0.0001)$ & $269(<0.0001)$ & $18.4(<0.0001)$ \\
\hline & Time $\mathrm{D}+\mathrm{NAC}$ & $3.5(0.008)$ & $1.25(0.30)$ & $0.81(0.55)$ & $3.5(0.009)$ & $1.16(0.34)$ \\
\hline $\mathrm{D}+$ Water vs & Time & $6.1(0.00019)$ & $1.95(0.10)$ & $4.8(0.0013)$ & $44(<0.0001)$ & $1.7(0.15)$ \\
\hline \multirow[t]{2}{*}{$\mathrm{D}+\mathrm{NAC}$} & NAC & $11.7(0.0013)$ & $0.34(0.56)$ & $6.11(0.017)$ & $48(<0.0001)$ & $6.3(0.016)$ \\
\hline & Time & $2.3(0.06)$ & $1.01(0.42)$ & $1.09(0.38)$ & $3.7(0.007)$ & $1.5(0.21)$ \\
\hline
\end{tabular}


Table 2. Glutathione levels in the muscle of the European eel during exposure to $0.17 \mathrm{mg} \mathrm{l}^{-1}$ dichlorvos for $96 \mathrm{~h}$ and/or recovery in clean water or a $0.5 \mathrm{mM} \mathrm{N}$-acetyl-L-cysteine (NAC) solution for $96 \mathrm{~h}$. Values are mean $\pm \mathrm{SE}(\mathrm{n}=5$ to 6$)$. Reduced (GSH) and oxidised (GSSG) glutathione levels were expressed in nmol GSx $\mathrm{mg}^{-1}$ protein. GSH:GSSG levels were expressed in number of molecules but not moles. D + Water and D + NAC were previously exposed to $0.17 \mathrm{mg} \mathrm{l}^{-1}$ dichlorvos for $96 \mathrm{~h} .{ }^{*},{ }^{* *},{ }^{* * *}: \mathrm{p}<0.05$, $\mathrm{p}<0.01$, and $\mathrm{p}<0.001$, respectively, compared to the control group. $\S$, $\S \S \S \mathrm{p}<0.05$ and $\mathrm{p}<0.001$, respectively, compared to the D + Water group

\begin{tabular}{|c|c|c|c|c|c|c|}
\hline & Time (h) & Control & NAC & Dichlorvos & D + Water & $\mathrm{D}+\mathrm{NAC}$ \\
\hline \multirow[t]{6}{*}{ GSH } & 3 & $17.0 \pm 2.2$ & $16.0 \pm 2.2$ & $14.3 \pm 1.1$ & $7.5 \pm 1.1^{* * *}$ & $9.0 \pm 1.9^{* *}$ \\
\hline & 6 & $17.6 \pm 0.7$ & $18.2 \pm 2.1$ & $13.6 \pm 1.3$ & $11.2 \pm 1.6^{* *}$ & $8.7 \pm 1.1^{* * *}$ \\
\hline & 12 & $16.5 \pm 1.6$ & $19.4 \pm 1.4$ & $12.8 \pm 1.4$ & $13.1 \pm 1.4$ & $16.9 \pm 1.3$ \\
\hline & 24 & $16.4 \pm 1.4$ & $20.5 \pm 1.3$ & $11.2 \pm 1.1^{*}$ & $11.5 \pm 1.9^{*}$ & $19.5 \pm 1.4 \S \S \S$ \\
\hline & 48 & $18.7 \pm 1.9$ & $24.7 \pm 1.6^{* *}$ & $10.4 \pm 1.4^{* * *}$ & $9.2 \pm 1.0^{* * *}$ & $14.1 \pm 2.2 \S$ \\
\hline & 96 & $17.8 \pm 2.2$ & $22.3 \pm 1.4^{*}$ & $8.7 \pm 1.2^{* * *}$ & $9.4 \pm 1.7^{* * *}$ & $12.9 \pm 2.2$ \\
\hline \multirow[t]{6}{*}{ GSSG } & 3 & $1.44 \pm 0.13$ & $1.39 \pm 0.18$ & $1.42 \pm 0.06$ & $2.04 \pm 0.23^{*}$ & $1.69 \pm 0.26$ \\
\hline & 6 & $1.32 \pm 0.13$ & $1.28 \pm 0.22$ & $1.42 \pm 0.12$ & $1.67 \pm 0.23$ & $1.61 \pm 0.21$ \\
\hline & 12 & $1.27 \pm 0.20$ & $1.26 \pm 0.11$ & $1.69 \pm 0.21$ & $1.76 \pm 0.06$ & $1.64 \pm 0.11$ \\
\hline & 24 & $1.23 \pm 0.08$ & $1.36 \pm 0.07$ & $1.83 \pm 0.24^{*}$ & $1.81 \pm 0.27^{*}$ & $2.21 \pm 0.15^{* * *}$ \\
\hline & 48 & $1.38 \pm 0.11$ & $1.59 \pm 0.22$ & $1.92 \pm 0.11^{*}$ & $1.53 \pm 0.10$ & $1.83 \pm 0.20$ \\
\hline & 96 & $1.39 \pm 0.21$ & $1.40 \pm 0.16$ & $2.28 \pm 0.29^{* *}$ & $1.29 \pm 0.17$ & $1.54 \pm 0.32$ \\
\hline \multirow[t]{6}{*}{ GSH:GSSG } & 3 & $23.9 \pm 3.2$ & $23.0 \pm 1.0$ & $20.3 \pm 2.0$ & $8.1 \pm 1.9^{* * *}$ & $10.8 \pm 1.9^{* * *}$ \\
\hline & 6 & $27.5 \pm 2.3$ & $30.2 \pm 2.9$ & $19.2 \pm 1.2^{* *}$ & $13.8 \pm 1.5^{* * *}$ & $11.1 \pm 1.2^{* * *}$ \\
\hline & 12 & $28.2 \pm 4.1$ & $31.7 \pm 3.0$ & $15.5 \pm 1.2^{* * *}$ & $14.9 \pm 1.6^{* * *}$ & $20.9 \pm 2.0 \S$ \\
\hline & 24 & $27.0 \pm 2.2$ & $30.2 \pm 1.4$ & $12.7 \pm 0.8^{* * *}$ & $13.3 \pm 2.0^{* * *}$ & $17.9 \pm 1.6^{*}$ \\
\hline & 48 & $28.1 \pm 4.2$ & $32.8 \pm 3.2$ & $10.7 \pm 1.0^{* * *}$ & $12.3 \pm 1.5^{* * *}$ & $15.6 \pm 2.1^{* *}$ \\
\hline & 96 & $26.7 \pm 3.0$ & $33.1 \pm 2.4^{*}$ & $7.6 \pm 0.5^{* * *}$ & $15.3 \pm 2.8^{* *}$ & $18.6 \pm 3.2^{*}$ \\
\hline
\end{tabular}

\section{Recovery}

Fish that were exposed to a sublethal concentration of dichlorvos for $96 \mathrm{~h}$ and transferred to clean water then continued with GSH depletion $(\mathrm{p}<0.0001$, Table 1), increased GSSG ( $p=0.0012)$, and a low GSH:GSSG ratio ( $p<0.0001$ ) in the muscle, and AChE and GR inhibition in the brain $(\mathrm{p}<0.0001)$. The recovery of brain AChE was time-dependent $(p=0.0006)$, with an interaction effect of time with treatment ( $p=0.05$ ).

When fish were allowed to recover in a $0.5 \mathrm{mM}$ NAC solution instead of only water, muscular GSH increased time-dependently ( $p=0.038$ ), with an interaction effect of time with the treatment $(p=0.008)$. Then, NAC treatment improved muscular GSH content $(\mathrm{p}=0.0013)$, which was increased by $69 \%$ at $24 \mathrm{~h}(\mathrm{p}<0.001)$ and $54 \%$ at $48 \mathrm{~h}(\mathrm{p}<0.05)$ compared to fish recovered in water. Although this GSH augment was concomitant to a GSSG increase at $24 \mathrm{~h}(\mathrm{p}<0.001)$, glutathione redox status was less oxidised than water-recovered fish $(p=0.017$, Table 1), being $40 \%$ higher at $12 \mathrm{~h}(\mathrm{p}<$ 0.05). Brain AChE activity increased over time $(p<0.0001)$ and was less inhibited than in water-recovered fish ( $p<0.0001)$, with an interaction effect of NAC with time ( $p=0.007)$. GR activity was also less inhibited in NAC-treated fish ( $p=0.016)$. NAC treatment then increased significantly, by $47 \%$, brain AChE recovery from 12 to $96 \mathrm{~h}$ (Fig. 1), being

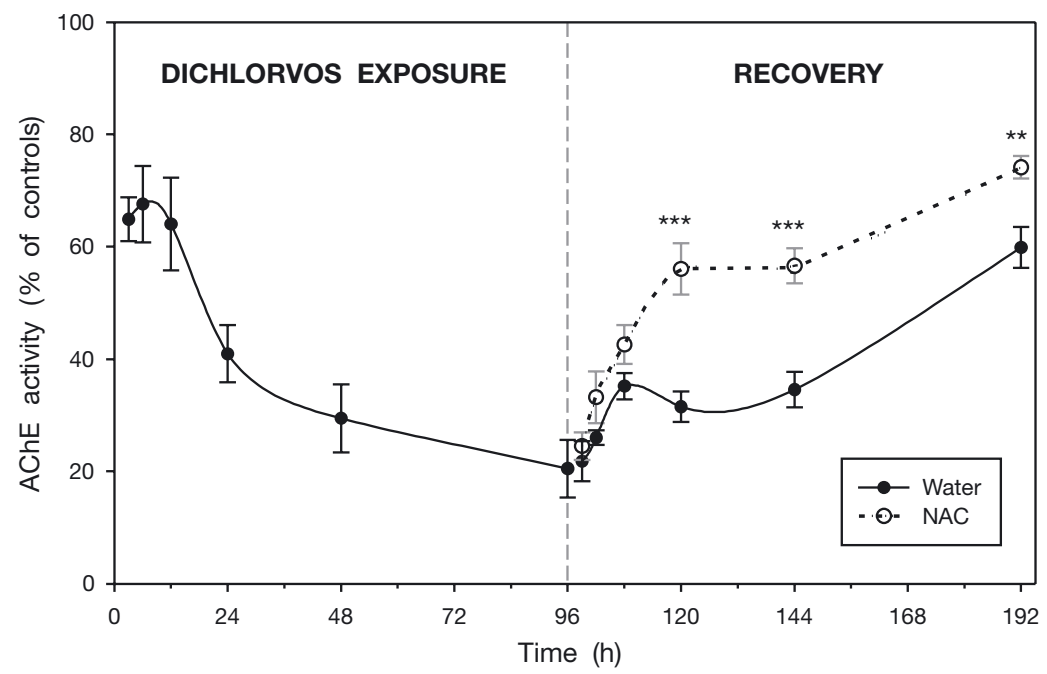

Fig. 1. Anguilla anguilla. Acetylcholinesterase (AChE) activity in the brain of the European eel after $96 \mathrm{~h}$ of exposure to $0.17 \mathrm{mg} \mathrm{l}^{-1}$ of dichlorvos and recovery for $96 \mathrm{~h}$ in clean water (solid line) or in $0.5 \mathrm{mM} \mathrm{N}$-acetyl-L-cysteine (NAC; dotted line). Control activity: $233 \pm 7 \mathrm{mU} \mathrm{mg}^{-1}$ protein. ${ }^{*},{ }^{* *},{ }^{* * *}: \mathrm{p}<0.05, \mathrm{p}<$ 0.01 , and $\mathrm{p}<0.001$, respectively, at each specific time 


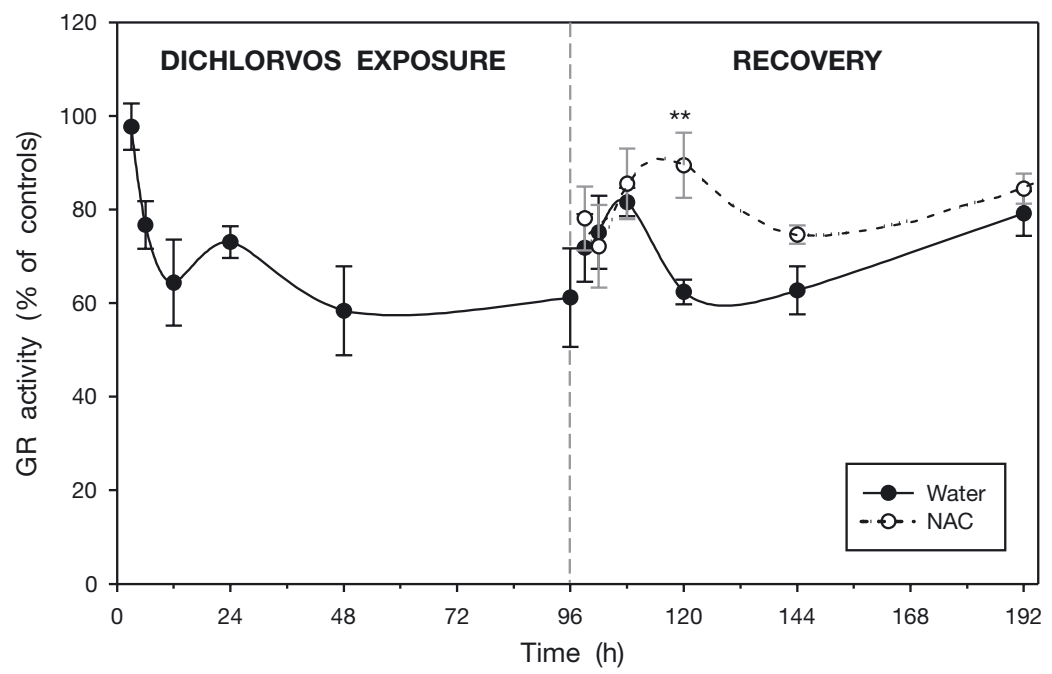

Fig. 2. Anguilla anguilla. Glutathione reductase (GR) activity in the brain of the European eel after $96 \mathrm{~h}$ of exposure to $0.17 \mathrm{mg} \mathrm{l}^{-1}$ of dichlorvos and recovery for $96 \mathrm{~h}$ in clean water (solid line) or in $0.5 \mathrm{mM} \mathrm{N}$-acetyl-L-cysteine (NAC; dotted line). Control activity: $31.8 \pm 1.2 \mathrm{mU} \mathrm{mg}^{-1}$ protein. ${ }^{* *} \mathrm{p}<0.01$ at each specific time

$78 \%$ higher at $24 \mathrm{~h}(\mathrm{p}<0.001)$, whereas GR inhibition was reduced by $43 \%$ after 24 h of recovery ( $p<0.01$; Fig. 2), returning to the control levels.

\section{DISCUSSION}

The present work demonstrates that the antioxidant and glutathione pro-drug NAC improves the recovery from dichlorvos poisoning in the European eel. A sublethal concentration of this OP pesticide $\left(0.17 \mathrm{mg} \mathrm{l}^{-1}\right.$, $20 \%$ of the $96 \mathrm{~h} \mathrm{LC}_{50}$ ) decreased and oxidised muscular GSH levels, declining the GSH:GSSG ratio, which is indicative of a process of oxidative stress. In addition, AChE and GR activities were inhibited in the brain. These results are consistent with the data of Hai et al. (1997), who have shown GSH decrease in the liver and muscle of the common carp Cyprinus carpio, and inhibition of the brain AChE activity after being exposed to 1 and $5 \mathrm{mg} \mathrm{l}^{-1}$ of dichlorvos for $24 \mathrm{~h}$.

Dichlorvos is metabolised mainly in the liver via 2 enzymatic pathways: one, producing desmethyldichlorvos, is glutathione-dependent, while the other, resulting in dimethyl-phosphate and dichloroacetaldehyde, is glutathione-independent (Dicowsky \& Morello 1971). Hence, GSH availability can result in a limiting factor for dichlorvos elimination. Although de novo synthesis of glutathione by glutamate-cysteine ligase (GCL) is regulated by feedback inhibition of GSH (Richman \& Meister 1975), NAC baths increased muscular GSH content. Furthermore, NAC treatment ameliorated muscular GSH depletion.
The relationship between AChE inhibition and mortality is species- and agespecific, but normally a brain AChE inhibition higher than $70 \%$ is associated with mortality (Fulton \& Key 2001). In the present study, brain AChE inhibition in dichlorvos-exposed fish increased over time and reached $80 \%$ of the control activity after $96 \mathrm{~h}$ exposure, but no mortality was experienced. Sancho et al. (1997) found a $64 \%$ inhibition of brain AChE in European eels exposed for $96 \mathrm{~h}$ to a sublethal $(20 \%$ of the corresponding $96 \mathrm{~h} \mathrm{LC}_{50}$ ) concentration of the OP insecticide fenitrothion, which is a less potent cholinesterase inhibitor than dichlorvos because it requires activation to the oxygen analogue fenitrooxon.

The recovery of brain AChE activity is a function of the degree of the initial inhibition (Morgan et al. 1990). As the recovery of enzyme activity is basically a result of the de novo synthesis of enzyme protein, the greater the degree of inhibition, the more protein synthesis is required (Fulton \& Key 2001). Sancho et al. (1997) found that the AChE inhibition of fenitrothionintoxicated fish decreased from 64 to $49 \%$ and $37 \%$ after 96 and 192 h, respectively, of recovery in clean water. In the current study, brain AChE was still inhibited by $40 \%$ after $96 \mathrm{~h}$ of recovery in clean water, but only by $26 \%$ in the $0.5 \mathrm{mM}$ NAC solution. These results indicate that bath treatments with NAC enhance the recovery of AChE activity, which to our knowledge have not been previously reported without the use of an oxime to reactivate the inhibited AChE.

In a recent study (Peña-Llopis et al. in press), NAC treatment extended the survival of European eels exposed to a lethal concentration of dichlorvos. This survival was especially associated to the maintenance of the hepatic glutathione redox status, muscular AChE and GR activities, muscular GSH levels, and hepatic GCL activity. However, in the preliminary experiments, high concentrations of NAC were lethal to fish. These mortalities might be due to the metal-catalysed ROS generation by NAC, because very high doses of lowmolecular-weight thiols can be pro-oxidants instead of antioxidants, and result in their transition metal-dependent autooxidation yielding $\left(\mathrm{O}_{2} \cdot^{-}\right), \mathrm{H}_{2} \mathrm{O}_{2}$, and the reduced form of the transition metal, which may behave as a catalyst in free-radical formation (Sprong et al. 1998). Therefore, control of the antioxidant concentration is crucial in order to avoid its adverse effects.

The hypothesis of the implication of the glutathione metabolism in dichlorvos toxicity is summarised in Fig. 3. The inhibition of brain AChE activity by OP 


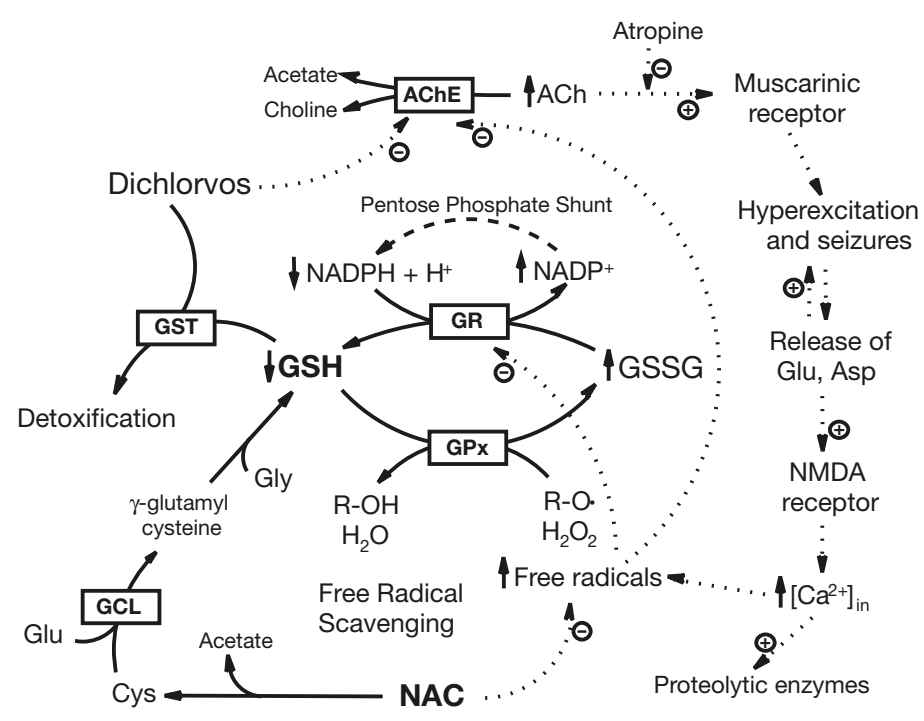

Fig. 3. Scheme of the proposed involvement of the glutathione metabolism in the toxicity of dichlorvos based on the present and other studies. Organophosphate (OP) inhibits the brain acetylcholinesterase (AChE) activity, leading to excessive accumulation of acetylcholine (ACh) and overstimulation of muscarinic receptors. This process produces neuronal hyperexcitation and seizures that allow the release of excitatory amino acids, such as glutamate (Glu) and aspartate (Asp), which activate the $N$-methyl-D-aspartate (NMDA) receptor. Excessive activation of NMDA receptors triggers the influx of large amounts of extracellular $\mathrm{Ca}^{2+}$, which activates proteolytic enzymes and leads to formation of free radicals. Then, reduced glutathione (GSH) oxidises to glutathione disulfide (GSSG) to remove the reactive oxygen species, catalysed by glutathione peroxidase (GPx) or non-enzymatically. GSSG is subsequently reduced to GSH by glutathione reductase (GR) at the expense of oxidising NADPH to $\mathrm{NADP}^{+}$, which is recycled by the pentose phosphate pathway. In addition, GSH can be conjugated to dichlorvos by glutathione $S$-transferases (GST), allowing the detoxification of the pesticide. The antioxidant $N$-acetyl-L-cysteine (NAC) acts as a reductant and free-radical scavenger that can also be deacetylated to cysteine (Cys), the limiting amino acid for glutathione synthesis, which is regulated by glutamate-cysteine ligase (GCL)

pesticides blocks the hydrolysis of the neurotransmitter acetylcholine (ACh), which can accumulate and activate muscarinic receptors. The overstimulation of cholinergic neurones initiates a process of hyperexcitation and convulsive activity that progresses rapidly to status epilecticus, which leads to profound structural brain damage or the death of the organism if the muscarinic $\mathrm{ACh}$ receptor antagonist atropine is not swiftly administered. These OP-induced seizures allow the release of excitatory amino acids, such as glutamate and aspartate, prolonging the convulsive activity, and making atropine treatment ineffective (Shih \& McDonough 1997). High concentrations of these excitatory amino acids can activate the $N$ methyl-D-aspartate (NMDA) receptor, leading to an intracellular influx of $\mathrm{Ca}^{2+}$, which triggers the activation of proteolytic enzymes and free radical generation (Beal 1995). These effects can be attenuated or reversed using NMDA receptor antagonists (Solberg \& Belkin 1997). Free radicals may, in addition, inhibit the activity of AChE, probably by oxidation of an amino acid critical for enzyme function (Den Hartog et al. 2002), and prevent the recovery of the enzyme function.

Cytosolic free radicals are either removed nonenzymatically or by antioxidant enzymes such as superoxide dismutase and glutathione peroxidase (GPx), which oxidises GSH to GSSG (Fig. 3). GSSG is then reduced back to GSH by glutathione reductase (GR) through oxidation of $\mathrm{NADPH}$ to $\mathrm{NADP}^{+}$, which is recycled by the pentose phosphate pathway. Raising the GSH:GSSG ratio by reducing GSSG to 2 molecules of GSH is energetically less costly than synthesising GSH de novo, which is regulated by the enzyme GCL. Furthermore, glutathione $S$-transferases (GST) catalyse the conjugation of GSH to the OP pesticide, leading to its detoxification and elimination. Bath treatments with NAC were a source of the limiting amino acid Cys to synthesise glutathione when it is depleted, enhancing the detoxification of the OP. NAC acts also as a reductant and free radical scavenger, ameliorating the enzyme inhibition caused by the free radicals generated by dichlorvos.

Despite the widespread applications and extensive use of dichlorvos since its commercial introduction in 1961, the US Environmental Protection Agency (US EPA) had made public in 1995 its intention to cancel several dichlorvos registrations, because it was classified as a possible carcinogen for man (US EPA 1995). Detailed examination of the animal experimental data by independent experts eventually concluded that no measurable cancer hazard can legitimately be associated with exposure to dichlorvos (Mennear 1998), and downgraded its classification toward 'non-classifiable with regard to cancer in man' (Van Maele-Fabry et al. 2000). However, its use is banned in the UK for bath treatments of fish against sea lice infestations (Costello et al. 2001), and as it presented reduced efficacy caused by parasite resistance (Jones et al. 1992), it has been replaced by other OPs like azamethiphos (Roth et al. 1996). This insecticide was also found useful to treat parasite infestations in the European eel (Pretti et al. 2002).

Although the standard treatment against OP poisoning consists of reactivation of the inhibited AChE with an oxime, and reversal of the biochemical effects of acetylcholine with atropine through an intravenous or 
intraperitoneal injection (Kwong 2002), the present study demonstrates that NAC may be a complementary antidote for OP poisoning, acting at different target sites: it increases the detoxification of the OP and the removal of ROS. In addition, the advantages of NAC compared to atropine and pralidoxime therapy are that NAC is less expensive and can be administered by bath. The current work also creates the possibility of treating not only accidentally organophosphate-poisoned fish, but also intoxicated fish after antiparasitic actions, without time-consuming injections. This is especially important in the case of treatment of parasitic infestations in warm waters, because temperature generally increases the toxicity of pesticides, representing a risk for fish health. This is the case for the culture of European eel in recirculated freshwater, or marine farms of sea bream Sparus aurata and sea bass Dicentrarchus labrax in the Mediterranean, which are infested by cymothoid isopods (Horton \& Okamura 2001), and the use of pesticides is encouraged (Papapanagiotou \& Trilles 2001).

\section{Conclusions}

NAC improves fish recovery from a sublethal concentration of dichlorvos through enhancing the glutathione metabolism and decreasing the glutathione loss and oxidation, and enzyme inactivation caused by the OP pesticide. Therefore, NAC increases the tolerance to dichlorvos-induced oxidative stress, being a potential antidote for OP poisoning that can be administered by bath. However, NAC concentrations should be controlled because very high doses may be harmful to fish health.

Acknowledgements. This work was supported by the CICYTFEDER grant 1FD1997-0943-CO2-02. S.P.-L. is recipient of a research grant from the Spanish Council for Scientific Research (CSIC). The fish farm Valenciana de Acuicultura S.A. is greatly acknowledged for kindly providing the European eels.

\section{LITERATURE CITED}

Bagchi D, Bagchi M, Hassoun EA, Stohs SJ (1995) In vitro and in vivo generation of reactive oxygen species, DNA damage and lactate dehydrogenase leakage by selected pesticides. Toxicology 104:129-140

Baker MA, Cerniglia GJ, Zaman A (1990) Microtiter plate assay for the measurement of glutathione and glutathione disulfide in large numbers of biological samples. Anal Biochem 190:360-365

Beal MF (1995) Aging, energy, and oxidative stress in neurodegenerative diseases. Ann Neurol 38:357-366

Brigelius R, Lenzen R, Sies H (1982) Increase in hepatic mixed disulphide and glutathione disulphide levels elicited by paraquat. Biochem Pharmacol 31:1637-1641

Costello MJ, Grant A, Davies IM, Cecchini S, Papoutsoglou S, Quigley D, Saroglia M (2001) The control of chemicals used in aquaculture in Europe. J Appl Ichthyol 17: $173-180$

Cribb AE, Leeder JS, Spielberg SP (1989) Use of a microplate reader in an assay of glutathione reductase using 5,5'-dithiobis(2-nitrobenzoic acid). Anal Biochem 183:195-196

Den Hartog GJ, Vegt E, van der Vijgh WJ, Haenen GR, Bast A (2002) Hypochlorous acid is a potent inhibitor of acetylcholinesterase. Toxicol Appl Pharmacol 181: 228-232

Dicowsky L, Morello A (1971) Glutathione-dependent degradation of 2,2-dichlorovinyl dimethyl phosphate (DDVP) by the rat. Life Sci II 10:1031-1037

Doctor BP, Toker L, Roth E, Silman I (1987) Microtiter assay for acetylcholinesterase. Anal Biochem 166:399-403

Ellman GL, Courtney KD, Andres V, Featherstone RM (1961) A new and rapid colorimetric determination of acetylcholinesterase activity. Biochem Pharmacol 7:88-95

Ferenczy J, Szegletes T, Bálint T, Ábrahám M, Nemcsók $\mathrm{J}$ (1997) Characterization of acetylcholinesterase and its molecular forms in organs of five freshwater teleosts. Fish Physiol Biochem 16:515-529

Ferrando MD (1990) Toxicidad de pesticidas organoclorados y organofosforados en Anguilla anguilla: alteraciones fisiológicas producidas en la anguila tras la intoxicación con lindano. PhD thesis, University of Valencia

Fulton MH, Key PB (2001) Acetylcholinesterase inhibition in estuarine fish and invertebrates as an indicator of organophosphorus insecticide exposure and effects. Environ Toxicol Chem 20:37-45

Hai DQ, Varga SI, Matkovics B (1997) Organophosphate effects on antioxidant system of carp (Cyprinus carpio) and catfish (Ictalurus nebulosus). Comp Biochem Physiol 117C: 83-88

Henriksson J, Chi MM, Hintz CS, Young DA, Kaiser KK, Salmons S, Lowry OH (1986) Chronic stimulation of mammalian muscle: changes in enzymes of six metabolic pathways. Am J Physiol 251C: 614-632

Horton T, Okamura B (2001) Cymothoid isopod parasites in aquaculture: a review and case study of a Turkish sea bass (Dicentrarchus labrax) and sea bream (Sparus auratus) farm. Dis Aquat Org 46:181-188

Jones MW, Sommerville C, Wootten R (1992) Reduced sensitivity of the salmon louse Lepeophtheirus salmonis, to the organophosphate dichlorvos. J Fish Dis 15:197-202

Kwong TC (2002) Organophosphate pesticides: biochemistry and clinical toxicology. Ther Drug Monit 24:144-149

Meister A, Anderson ME (1983) Glutathione. Annu Rev Biochem 52:711-760

Mennear JH (1998) Dichlorvos: a regulatory conundrum. Regul Toxicol Pharmacol 27:265-272

Morgan MJ, Fancey LL, Kiceniuk JW (1990) Response and recovery of brain AChE activity in Atlantic salmon exposed to fenitrothion. Can J Fish Aquat Sci 47:1652-1654

OECD (Organisation for Economic Cooperation and Development) (1992) Guidelines for the testing of chemicals 203: fish, acute toxicity test. OECD, Paris

Papapanagiotou EP, Trilles JP (2001) Cymothoid parasite Ceratothoa parallela inflicts great losses on cultured gilthead sea bream Sparus aurata in Greece. Dis Aquat Org 45: 237-239

Peña S, Peña JB, Ríos C, Sancho E, Fernández C, Ferrando MD (2000) Role of glutathione in thiobencarb resistance in the European eel Anguilla anguilla. Ecotoxicol Environ Saf 46:51-56 
Peña-Llopis S, Peña JB, Sancho E, Fernandez-Vega C, Ferrando MD (2001) Glutathione-dependent resistance of the European eel Anguilla anguilla to the herbicide molinate. Chemosphere 45:671-681

Peña-Llopis, S, Ferrando, MD, Peña, JB (in press) Fish tolerance to organophosphate-induced oxidative stress is dependent on the glutathione metabolism and enhanced by $N$-acetylcysteine. Aquatic Toxicol

Pretti C, Soldani G, Cognetti-Varriale AM, Monni G, Meucci $\mathrm{V}$, Intorre L (2002) Efficacy and safety of azamethiphos for the treatment of pseudodactylogyrosis in the European eel. J Vet Pharmacol Ther 25:155-157

Richman PG, Meister A (1975) Regulation of gammaglutamyl-cysteine synthetase by nonallosteric feedback inhibition by glutathione. J Biol Chem 250:1422-1426

Riddles PW, Blakeley RL, Zerner B (1979) Ellman's reagent: 5,5'-dithiobis(2-nitrobenzoic acid)-a reexamination. Anal Biochem 94:75-81

Roth M, Richards RH, Dobson DP, Rae GH (1996) Field trials on the efficacy of the organophosphorus compound azamethiphos for the control of sea lice (Copepoda: Caligidae) infestations of farmed Atlantic salmon (Salmo salar). Aquaculture 140:217-239

Sancho E, Ferrando MD, Andreu E (1997) Response and recovery of brain acetylcholinesterase activity in the European eel, Anguilla anguilla, exposed to fenitrothion. Ecotoxicol Environ Safety 38:205-209

Shih TM, McDonough JH Jr (1997) Neurochemical mechanisms in soman-induced seizures. J Appl Toxicol 17:255-264

Editorial responsibility: Thomas Braunbeck, Heidelberg, Germany
Smith IK, Vierheller TL, Thorne CA (1988) Assay of glutathione reductase in crude tissue homogenates using 5,5'-dithiobis(2-nitrobenzoic acid). Anal Biochem 175: 408-413

Solberg Y, Belkin M (1997) The role of excitotoxicity in organophosphorous nerve agents central poisoning. Trends Pharmacol Sci 18:183-185

Sprong RC, Winkelhuyzen-Janssen AM, Aarsman CJ, van Oirschot JF, van der Bruggen T, van Asbeck BS (1998) Low-dose $\mathrm{N}$-acetylcysteine protects rats against endotoxin-mediated oxidative stress, but high-dose increases mortality. Am J Respir Crit Care Med 157:1283-1293

US EPA (US Environmental Protection Agency) (1995) Dichlorvos: notice of preliminary determination to cancel certain registrations and draft notice of intent to cancel. Federal Register, Vol 60, No. 188. US EPA, Washington, DC

Van Maele-Fabry G, Laurent C, Willems JL (2000) Dichlorvos and carcinogenicity: a systematic approach to a regulatory decision. Regul Toxicol Pharmacol 31:13-21

Van Waarde G, Van den Thillart G, Keskebe F (1983) Anaerobic energy metabolism of the European eel Anguilla anguilla. J Comp Physiol 149:73-86

WHO (World Health Organisation) (1989) Environmental health criteria 79: dichlorvos. International program on chemical safety. WHO, Geneva

WHO (World Health Organisation) (1990) Environmental health criteria 103: 2-Propanol. International program on chemical safety. WHO, Geneva

Submitted: October 4, 2002; Accepted: April 23, 2003

Proofs received from author(s): July 11, 2003 